\title{
Research of the Food Safety Management Innovation Based on the Internet Thinking
}

\author{
Du Tianyu \\ Tianjin University of Science \& Technology, Tianjin 300222 \\ aike1217@sina.com
}

\begin{abstract}
Keywords: Food safety management; Internet thinking; Collaborative innovation
\end{abstract}
\begin{abstract}
With the social and economic development, people's living standards continuing to improve, together with the development of the Internet era of new media, fair consciousness and right consciousness of consumers and other public has increases, they begin to pay more attention to the food safety problems, reflect more and more passionately, the varying degree and the enthusiasm of participation in the governance of food safety problems of non-governmental organizations such as the food industry association and society is becoming more and more high. Fully mobilize the enthusiasm and initiative of each participation main body, go the way of food safety management of collaborative innovation, to greet the "Internet + " intelligent era. Through analyzing our country present stage, the problems existing in the supervision of food safety governance, finally put forward measures and suggestions of food safety management based on the perspective of Internet innovation and, so as to provide certain theory instruction in food safety governance.
\end{abstract}

\section{Introduction}

The traditional system design centering on the regulation is becoming more and more ragged in front of the increasingly complicate food safety problem. Multiple cooperative governance has become the more important way to solve the problem of food safety. National food safety strategy, the concept of "healthy China" is put forward, which puts forward the new requirements to correctly deal with food safety problems. How to use the Internet to provide consumers with fast and convenient way of consumption, develop more effective and practical food safety regulation is the issues of mutual interest of government, enterprises, consumers and academic. The food safety regulation needs to use social work concept to solve the problem in the era of "Internet + ".

Food security strategy is mentioned in the construction of "healthy China", food safety is the basic livelihood issues. In the internet age, adopting more effective and more convenient way to do well the social food safety work is imminent.

\section{The Main Problems Existing in the Present Food Safety Management}

\subsection{Government-wide}

2.1.1Food Safety Regulatory System Has Defects On the surface, the responsibilities and the scope of regulatory of various related department is clear, distinct functions, their respective make implementation within the scope of regulation, however, in fact, noncooperation and being uncoordinated between regulators occur due to the imperfect supervision system. The repetition, cross, conflict and contradiction of the scope of supervision of some regulators and the offside, absence and dislocation and omission phenomenon occurs frequently, leading to a lot of blind spots and blank of regulatory ${ }^{[1]}$. Scramble to regulatory for short-term interests and mutual shuffle when need to bear the responsibility in meeting food safety accident.

2.1.2The Food Safety Testing Standards Is Backward and Not Unified Some food safety governance standards cannot be revised timely, and is difficult to adapt to the social development level, overlapping and inconsistent problems, poor compatibility and poor coordination exist in every 
link of production, processing, circulation and standard. There are many safety standards and testing methods in the same products which make the government regulators not figure out.

\subsubsection{The Government Regulation Behavior Exists Self-interesting and the Accountability} Mechanism Is Not Perfect In the process of participating in food safety governance, because of sector interests and local interests, some food companies and government regulators plot together, become the interests' representatives of the food producers and business operators, inaction or abusing of power of the government's food safety regulatory organizations, departments mutual prevarication shuffle in order to avoid regulatory responsibilities in the food safety incident, such an irresponsible government image, left a bad impression in the eyes of the public, seriously influenced the government's credibility and public trust. Government regulation of questionable and credibility eroded gradually.

Establishing the accountability mechanism, so as to strengthen implement regulatory responsibility, however, due to the imperfect present system, it is difficult to operate actually, the main responsibility of the regulators punishment force is far away from it supposed to be, punishment of the dereliction duty by government law enforcement personnel is only administrative authority which has nothing to do with the key, rarely investigated the main departments of responsibility, penalties is too small and a deterrence is in serious shortage.

2.2 The Level of Food Enterprise There is serious information asymmetry phenomenon in the food markets which manifest as that the food production enterprises do know their product quality, but in order to obtain greater profits, deliberately concealed unfavorable information for consumers, some companies even shoddy, which makes consumers don't have access to all the food information or fail to ensure that the actual reliability of the information obtained." Interest doctrine "prevails in the food industry area, some food companies take vicious competition in pursuit of profits, turned a blind eye to the public health, the production materials in violation of the provisions national food quality standard is widely used, or even violated the national law. However, as part of the victims being an insider, didn't take action to stop and reflect these potential food safety problems, just turn a blind eye. The public"indulge"in the unqualified enterprises which make the relevant food companies be more rampant and reckless.

Our country's food safety management system and mechanism, the imperfect laws and regulations and management measures are not complete. Lax regulation and poorly punishment in the varieties of illegal behavior in the process production and processing and management of food, which let some food enterprises who don't have the heart of the moral violate but often can get by. Food safety incidents happen frequently, which brings harm to the human health and social harmony at the same time, have serious negative effects to enterprise reputation, make itself be in bad odour and abandoned by the market in the end.

2.3 The Consumer Level Popularity on the credibility propaganda and education about the food safety by the government does not reach the designated position, which makes consumers' basic knowledge of food safety is not enough, responsibility consciousness, safety consciousness, consciousness of citizen's rights and supervision are all insufficient, affecting the quality of food safety. Because there is no unified platforms for special collection, sharing and distributing food information, information that consumers get are often distortion and lag, consumers easily become passive victims of food safety problems. In the case of asymmetric information, in the game of the consumers and enterprises, consumers are always at a disadvantage position, less understanding of knowledge about food safety related laws and regulations, consciousness and ability of participating in the governance of food safety is not strong, the participation channels and way of activist are not unblocked, the high cost of rights protecting, which leads to that maintaining their own legitimate rights and interests is strong in will but weak in power.

2.4 The Food Industry Association Level Due to the dual insufficient of legal system supply and the empowerment of government in our country, the autonomy function of profession association is weak. Food industry association, rarely implement activities on consumers and pay less attention to disclosing the relevant food safety information to the society and consumers, lack of the 
consciousness of making information communication with consumers. Excessive emphasis on the interests of the food enterprises and industry to maintain and ignoring the effective communication with society and consumers is one major drawback of the function orientation the food industry association.

2.5 Social Organization Level The government doesn't have focused its efforts on nurturing and supporting the social organization, the imperfection of the relevant laws and regulations, the absence of the legitimacy status of the social groups ${ }^{[2]}$. In addressing the problem of food security, lack of credibility, humbled, based on such background, the advantage of social organizations participating in the governance of food safety obviously is not evidence.

If the traditional regulatory system, system and testing standard and technical level blocked channels through which non-governmental organizations participate in governance, then, the development of the internet provides a technology platform for the food safety of multiple cooperative governance.

\section{The Connotation of the Internet Thinking and Correspondence with the Concept of the Food Safety Management}

3.1 The Connotation of Internet Thinking The Internet thinking is put forward by Li Yanhong, the founder of Baidu Inc., as the earliest one ${ }^{[3]}$. He said, we being entrepreneurs will have the internet thinking in the future, maybe what you are doing have nothing to do with the internet, but the way you think will gradually from the perspective of the Internet to think problem ${ }^{[4]}$.In the past a few years now, this concept has been gradually recognized by more and more entrepreneurs, and each person from all walks of life, in various field even out of enterprises.

The internet thinking is that under the background of the development of science and technology such as the (mobile) internet + , big data and cloud computing, one way of thinking to re-examine the market, customers, products, enterprise value chain and even the whole business ecosystem ${ }^{[5]}$. These ways of thinking are not following the internet, on the contrary, because of emergence and development of the internet, the mind can breakout centrally.

3.2 The Internet Thinking Is Corresponded with the Food Safety Management First of all, both emphasis on multivariate main body participation. Food safety governance emphasizes the multi-agent collaborative governance, maintenance requires that those responsible and all stakeholders of food safety including government, food industry, consumer food industry association and social organizations, etc., it refers the whole society to participate ${ }^{[6]}$. The internet thinking emphasizes the open ecosystem concept of connectivity and sharing work, emphasizes on that multiple correlation subjects try to achieve the common value goal by mutual benefit, mutual cooperation, even cross-border integration, thus form an organic whole.

Second, both stress making quick, timely and effective response to the need of the public ${ }^{[7]}$. Food safety governance requires regulatory entity to actively understand the need and opinion of the society and give reply timely and effective response when formulating and implementing policies and regulations. When food safety events occur, the government should actively deal with, give the interpretation of truth of it to the mass objective. The internet links governance body and the social public closely together, providing convenient conditions and channels for the citizens to enjoy the right to know, to participate, to express and to supervise and play an increasingly important role in the government understanding public opinion and meeting the needs of the people, rapidly making response to the public opinion and safeguarding the interests of the people.

In the end, both of which emphasize the information transparency ${ }^{[8]}$. Food safety management requires that safety supervision of the administrative licensing, administrative penalties, food production standards, food safety law enforcement and other aspects of information all related to food shall take the initiative to be open ${ }^{[9]}$. The internet wiped out the monopoly of traditional media, the public with the help of the internet providing convenience to access and understand complete information, express individual desire and demand directly and participate in the supervision of the 
government's political and social affairs, objectively promote open and transparent of the government information.

\section{With the Help of the Internet, Innovative Food Safety Governance}

The development of "Internet + " provides a powerful support and guarantee for the public to participate in food safety governance. In the process of food safety management, the food safety governance mechanism of public participation, social work should be improved, in the government's top-down encouragement, guidance and specification, along with the push from bottom to top, consciousness and rational of social, the governance body deal with food safety problems in cooperation and common governance.

4.1 Wake Up the Consciousness and Responsibility Food Safety of the Public, Guide the Public to Participate in Food Safety Governance Because the mass consumers are the ultimate eaters and the most direct stakeholders, consumers' participation is the most reasonable in food safety governance. To mobilize the public to participate in the management, the first thing to do is to make the public more comprehensive understanding of the food safety and regulatory information. The main measures can be taken from the following aspects:

(a)Perfect the science popularization education platform. Construct a comprehensive platform of food safety science popularization, publicity and education of in accordance with "new media, traditional media is complementary";

(b)Clear opinion-expressed complaint channels. Construct an independent complaint reporting website system, develop apps, establish reporting acceptance, rapid disposal, timely feedback and cash rewards rapid response system;

(c)Establish a social credit evaluation mechanism. Credit system construction in our country has always been a hot and difficult problem ${ }^{[10]}$. From the perspective of the internet thinking, establish the food safety credit evaluation system, based on the experience of the taobao, the public comments on net, through the way of introducing social evaluation.

4.2 In the Food Safety Administration, the Government Should Set Up the Internet - Big Data- Open Thinking The government, the main food safety regulator, in order to alleviate the current situation of food safety, make food safety management system innovation, further perfect the mechanism and methods of food safety legal system safeguard, construct the food safety management system, improve food safety management ability, establish and improve the efficient food safety information system and the trace ability system, which is the only way to be chosen to mitigate food safety crisis.

(a)The government regulators can rely on the internet to establish a fast and effective food safety information transmission mechanism, so as to timely release detection information in food production and circulation, provide information technology platform to help consumers to participate in improving food safety control management;

(b)Use big data, cloud computing, internet and mobile internet to construct food safety risk early warning and response platform; Set up big data analysis platform of sampling observation of quality food companies, for each link, timely analysis, quality of the food and master, through the risk identification, timely adjustment of regulatory focus;

(c) Establish a network public opinion analysis system, through public opinion, timely grasp public opinion to control food safety public emergency; Establish consumer complaints reported large data analysis platform, early control from the reported data and timely elimination of food safety risk to minimize public harm to consumers;

(d)In accordance with the "government guidance, enterprise responsibility, social supervision and trace the whole process, reputation" demonstration of the idea to establish food trace ability system production and sales of the whole process ${ }^{[11]}$. 


\subsection{Strengthen the Management of the Internet Itself. \\ 4.3.1The Deficiency and Influence of the Internet in the Food Safety Information Dissemination}

(a)The food safety information is not true. The internet is easy to operate, by copying and pasting, through the unlimited expansion of infinite links, information can be easily, once there is the sudden food safety incident, some exaggerated internet rumors, and they will be spread in a very short period of time, resulting in public panic.

(b)Food information is large and very complex. A lot of food information enlarged the range of consumer choice, meet the needs of the public. But at the same time, the internet is full of spam, internet users searching really valuable information is difficult as the search for a needle in a haystack. For food safety information transmission on the network, people tend to choose the disadvantages, then they will become very sensitive, often the barrier of the other information leads to the late arrival of the correct information.

(c)The food information is asymmetry. To some extent, the internet in food safety in the process of information transmission make the information more asymmetry ${ }^{[12]}$. Using of consumers "ignorant" and the characteristics of the low threshold and the rapid spread of the Internet information, some food companies exaggerated propaganda, some features of fictional food, in order to achieve more profit, not introduce the product that may cause the adverse consequences, in order to increase sales, with cooperation of some network "star", let them endorsement and recommend products, leading consumers to the information confusing area.

(d) The food safety information transmission has hysteretic nature, After the food safety incident, for the interests of the department or local protectionism and maintaining company's reputation and image, from a certain extent, the government try to hide and suppress the truthfulness of food events, even ban the news media, the media's reporting lost its credibility, the public panic cannot get the exact information, rumors spread, the entire food industry becomes turmoil, the government's credibility and enterprise reputation are damaged.

4.3.2 Strengthen the Guidance and Utilize the Advantage of the Internet in the Food Safety Management Control the spread of the internet food safety information through legislation. integrate and comb the existing relevant laws and regulations, detail the broad ambiguous provisions of regulations, makes them feasible good system; On the macro level, establish a complete set of system of informative laws and regulations, from the perspective of legal, standard the content, nature and quality of spreading information.

Improve the technology to control the content of the internet communication ${ }^{[13]}$. Strengthen capital investment of technology to control the spread of the internet content regulation, encourage this aspect of the invention. Food information publisher or food service operator volunteered to take the initiative to grading on the web site content, which can effectively control release of information.

Strengthen management and moral education. The Internet itself has the characteristics of openness, inclusiveness and interactivity and global, some deceive that the Internet is a paradise of freedom, can do whatever you want in this space, without the burden of using technical vulnerability to bad information dissemination behavior, thus to realize the benign spread of Internet information must focus on people. The providers, internet users and internet controls of internet content all need the Internet literacy training; To improve public moral consciousness and self-discipline behavior of Internet users, making Internet users abide by the moral rules and regulate the behavior of their spread in the internet information dissemination process.

\section{The Conclusion and Prospect}

Food safety issues are the joint project of the concern from all aspects of life, which needs vigorously promoting social work, making the regulation together. Governments, consumers, food industry, food industry association as well as various social organizations and other relevant stakeholders does its proactive with full enthusiasm to participate in the food safety management. The government play a regulatory role, consumers actively cooperate with, enterprise autonomy, self-discipline, social 
organization supervision, do collaborative work. In addition, strengthen the cooperation among different subjects, such as government and enterprises in food information and data sharing, to help the government to improve the rules of its own information platform. Parties make joint efforts to the functions of the government, the protection of the rights and interests of consumers, the enterprise development, food industry development, social stability, synergy, build a benign "Internet + " food safety ecosystem. Believe that the emergence of the Internet platform should be a chance for the food safety regulation, and not a problem. Meet the challenge, seize the opportunity, meet the "Internet +" intelligent era.

\section{References}

[1] Liu. Food safety risk management research based on the Internet-- -- information tools perspective [J]. Journal of shanxi agricultural university (social science edition), 2016 (10) : 740-744.

[2] Stephen L.Vargo,Heiko Wieland et al. Innovation through institutionalization :A service ecosystems perspective[J].Industrial Marketing Management,2015,44:63-72.

[3] GiedriusJucevicius,Kristina Grumadaite. Smart development of innovation ecosystem[J].Procedia-Social and Behavioral Science,2014,156:125-129.

[4] Yi Kaigang,Fan Lin-lin . The concept of food safety governance reform and mechanism innovation [J]. Journal of academic journal, 2014, (12) : 41-48

[5] Ye Jun ,Wang Junhua. Chinese food safety supervision mechanism under the collaborative theory Angle of view research [J]. Chinese health service management, 2012, (7) : 504-506

[6] ZhaoCuiping, LiYongtao, ChenZishuai. Stakeholders in food safety governance responsibility: government, enterprise and consumer dimension analysis [J]. Journal of economic issues, 2012 (6) : 63-66

[7] Xia Haiqing. Coupling mechanism of food safety management research in China [19]. Journal of economic BBS, 2014 (11) : 26-27

[8] Stephen L.Vargo,Heiko Wieland et al. Innovation through institutionalization :A service ecosystems perspective[J].Industrial Marketing Management,2015,44:63-72.

[9] Adner R,Kapoor R. Value creation in innovation ecosystems: How the structure of chnological interdependence affects firm performance in new technology generation[J].Strategic anagement Journal,2010,31(3),306-333.

[10] GiedriusJucevicius,Kristina Grumadaite. Smart development of innovation ecosystem[J].Procedia-Social and Behavioral Science,2014,156:125-129.

[11] Cao,Z.,Zhang,L.,Feng,F.,Du,Y.(2013).Study on the Characteristics and Cultivating Path of the Industry-University Symbiotic Networks:Based on the Small-World Network Model and the Theory of Symbiosis.Asian Social Science,9(1):15-21.

[12] Feng,F.,Zhang,L.,Du,Y.,Ma,L.,Fu,M.(2012).Study on the classification and stability of industry-university-research symbiosis phenomenon:Based on the logistic model.Journal of Emerging Trends in Economics and Management Sciences,3(1):116-120.

[13] $\mathrm{Ng}$ Esmond Alin, Victoria. An Institutional Approach to theExamination of Food Safety[J]. International Food and AgribusinessManagement Review, 2012, 15 (2) : 21-45. 